\title{
DIVISÃO DO TRABALHO ODONTOLÓGICO EM PERSPECTIVA: DESAFIO DE INTERPRETAR AS COMPETÊNCIAS DOS TÉCNICOS
}

\author{
DIVISION OF DENTISTRY WORK IN PERSPECTIVE: THE CHALLENGE OF INTERPRETING \\ TECHNICIANS' ABILITIES
}

Carlo Henrique Goretti Zanetti ${ }^{1}$

José Antônio Abreu de Oliveira $^{2}$

Maria Helena Magalhães de Mendonça ${ }^{3}$

Resumo Com mais de cem anos de história, a divisão do trabalho odontológico é um processo afeto a princípios distintos, às vezes antagônicos: o profissional (social) e o administrativo (técnico/econômico). As circunstâncias geradas pelo dinamismo histórico desses princípios contendores recursivamente redefinem as possibilidades de sua operação. No Brasil de hoje, o brutal excedente de cirurgiões-dentistas na composição de força de trabalho odontológico tem gerado anomalias no processo de profissionalização da odontologia brasileira; ineficácia e injustiças no processo de racionalização e expansão da divisão de trabalho (trabalho em equipe) no Sistema Único de Saúde, em particular na atenção básica orientada pela Estratégia Saúde da Família; e a perpetuação de disputas interpretativas sobre os instrumentos normativos do ordenamento jurídico, tal como a lei n. 11.889/2008 que regulamenta as profissões de técnico em saúde bucal e de auxiliar em saúde bucal. Tudo isso são elementos cruciais para o futuro da organização de oferta de saúde bucal na atenção básica, bem como a disposição futura da força de trabalho no processo de transição epidemiológica em curso no país, hoje ainda excludente. Palavras-chave saúde bucal; técnico em saúde bucal; recursos humanos em saúde; saúde da família; divisão do trabalho em saúde.
Abstract With more than one hundred years of history, the division of labor in dentistry is a process that is affected by distinct and sometimes opposing principles: professional (social) and administrative (technical/economic). The circumstances created by the historical dynamics of these recursively contending principles redefine the possibilities of their operation. In Brazil today, the inordinate number of dentistry surgeons in the dentistry field has created anomalies in the professionalization process in Brazil, as well as ineffectiveness and unfairness in the rationalization process and expansion of the division of labor (team work) in the Public Health System (SUS), particularly with regards to the basic health care provided by the Family Health Strategy, and the perpetuation of interpretative disputes around normative instruments in the legal system, such as law no. $11,889 / 2008$, which governs the professions of buccal health technician and buccal health assistant. All of these are crucial elements for the future of the organization of the buccal health sector of basic health care, as well as the future disposition of the work force in the epidemiological transition process that is currently underway in the country.

Keywords buccal health; technician in buccal health; human resources in health; family health; division of labor in the health segment. 


\section{Introdução}

Em 2008, foi sancionada a lei n. 11.889, que regulamenta o exercício das profissões auxiliares de técnico em saúde bucal (TSB) e de auxiliar em saúde bucal (ASB) (Brasil, 2008). Ela consolidou conquistas profissionais, mas preservou antigos (e criou novos) problemas administrativos para o Sistema Único de Saúde (SUS), quando, por opção do legislador, a contenda histórica sobre a competência do TSB para a intervenção intrabucal direta, mediante procedimentos operatórios básicos restauradores e periodontais, supervisionados por cirurgiões-dentistas (CDs), foi mantida em aberto. Sem positividade legal, e agora ao alcance da jurisprudência, o sentido da divisão do trabalho restaurador no 'chão da clínica odontológica' continua carecendo de interpretação. A prescrição para que o TSB participe integralmente da atenção à saúde bucal no SUS é o âmago dessa controvérsia. Administrativamente, vislumbram-se consequências consideráveis sobre o planejamento e a programação das atividades clínico-odontológicas na oferta assistencial pública.

O porte dessas consequências justifica explorar as origens dessa contenda e compreender o ambiente político, econômico e social que informou a escolha do legislador. Para tanto, convergiram esforços acadêmicos anteriores e distintos dos autores deste artigo (Oliveira, 2008; Zanetti e Oliveira, 2009; Zanetti, 2010), numa nova síntese objetivada no exame dos antecedentes nacionais e internacionais da divisão do trabalho odontológico que pautaram o processo de institucionalização das profissões auxiliares no campo profissional da odontologia. Sem a memória dessas experiências, grande parte dos acontecimentos e dos desafios para o futuro não alcançarão adequada significação.

Apresenta-se aqui uma investigação de corte institucionalista históricoestrutural que tomou a divisão do trabalho odontológico como objeto empírico, transformando-o em objeto teórico ao tratá-lo conceitualmente como problema particular do antagonismo geral entre dois princípios de divisão do trabalho: o princípio profissional, um dos móbeis da divisão social do trabalho, e o princípio administrativo, móbil da divisão técnica do trabalho.

A hipótese é que a institucionalização da divisão do trabalho odontológico no Brasil contemporâneo tem se dado sob hegemonia do princípio profissional, bem como com a perda de foco do princípio administrativo. Daí decorre a desvalorização da importância dos TSBs na ampliação da oferta assistencial orientada pela Estratégia Saúde da Família (ESF) e, por derivação, uma sobrevalorização dos mesmos na atenção preventivo-promocional, prejudicando a incorporação dos agentes comunitários de saúde (ACSs) nas atividades da equipe de saúde bucal. 


\section{Antecedentes internacionais da divisão do trabalho odontológico}

\section{O berço norte-americano}

O processo de profissionalização da enfermagem nos Estados Unidos foi a pedra de toque para a elaboração das concepções sobre divisão do trabalho em saúde bucal, seja porque a relação medicina-enfermagem serviu de modelo para a relação odontologia-auxiliares no cenário das escolas, seja porque, naquele país, os novos conhecimentos e competências de higiene bucal foram inicialmente incorporados nas competências das enfermeiras visitadoras, em seus cenários de práticas: o centro de saúde e as famílias. Tanto o sucesso do seu desenvolvimento nas escolas quanto o seu fracasso nos centros de saúde e domicílios foram consequências do vigor do profissionalismo inventado como forma competitiva (interprofissional) de organização das oportunidades de mercado e de estratificação social nas sociedades anglo-americanas. Um profissionalismo inicialmente imerso no higienismo como paradigma sanitário, cujo ideal se propagou nesse país de cultura sociopolítica comunitarista (Tocqueville, 1987; Coelho, 1995) e progressivista (Progressivism in the United States, s.d.), os Estados Unidos, sobretudo através do trabalho das auxiliares visitadoras, notadamente desde a Guerra de Secessão (1861-1865).

Em saúde bucal, os novos conhecimentos higienistas norte-americanos fundaram preocupações com a prevenção de cárie e da doença periodontal, como também com a progressiva definição de novas competências profissionais. O ponto de partida dessa história é o trabalho clássico de Wilma Motley (1983). É uma história que começa nas primeiras décadas do século XIX, mas que só a partir de 1880 avançaria como um movimento higienista na odontologia, em defesa da inclusão da higiene nas escolas, e de leis que a garantissem.

Em 1890, W. D. Miller descreveu os microrganismos da boca e o aparecimento de cáries, munindo com evidências as preocupações higienistas da época. Técnicas de escovação foram criadas e a profilaxia apurada. Em 1894, D. D. Smith apud Motley (1983) ultrapassou os conceitos de simples limpeza, apresentando um sistema de profilaxia dos dentes com significativos resultados clínicos. Ainda nessa década, T. P. Hyatt apud Motley (1983) defendeu a participação de mães e professoras nas atividades regulares de higiene dental e F. W. Low apud Motley (1983) sugeriu que, para além das escolas, como competência profissional, fossem feitas visitas domiciliares, duas vezes por semana, para polir dentes.

Observa-se que, até fins do século XIX, enfermeiras visitadoras, professores e novos auxiliares foram indistintamente treinados para a higiene 
bucal em consultórios, escolas e domicílios, com competências estabelecidas inicialmente sem o signo da exclusividade profissional. Esse processo, porém, foi progressivamente acumulando tensões/disputas interprofissionais. Por isso, no início do século XX, M. L. Rhein apud Motley (1983) propôs a formação de enfermeiras dentais que ultrapassassem em eficiência as enfermeiras 'comuns', inclusive mencionando pioneiramente o tema da remoção de indutos. Indicou também como deveria se dar o processo de profissionalização das enfermeiras dentais (treinamento, exame, competências etc.) e obteve a aprovação da American Medical Association para a sua proposta.

Inspiradas em preocupações profissionalizantes odontológicas, surgiram contestações não apenas à nomenclatura utilizada (enfermeira dental), como também à pertinência ou não de formar essas auxiliares. Por um período de dez anos, 1905 a 1915, duas correntes de contendores se formaram: pró-higienistas dentais versus pró-enfermeiras dentais.

Liderando os contestadores, coube a Fones (Walls, 1949) cunhar, defender e consagrar a proposta das 'higienistas dentais', sob o argumento de que 'enfermeira' denotava doença, enquanto 'higienista' melhor se referia às especificidades do auxiliar. Na prática, esse reducionismo ao termo higienista significava criar um novo tipo de auxiliar desvinculado da conotação médica, marcando assim fronteiras jurisdicionais odontológicas exclusivas para o mesmo. Influenciado por Smith, Fones defendeu que o tema da saúde bucal tinha importância suficiente para autorizar o treinamento, acreditando ser a higienista a chave para um programa preventivo.

Essa defesa foi feita do alto de suas experiências acumuladas desde 1906, nas quais percebeu que os auxiliares contribuíam para a prática clínica, pois, dedicados à profilaxia e à higiene, deixavam o CD livre para os procedimentos restauradores. Fones inaugurou, assim, a divisão clínica profissional do trabalho odontológico por princípio profissional (competências em paralelo).

Em 1907, foi criada em Connecticut, por lei estadual, a profissão de 'higienista dental', com competências para instrução sobre higiene bucal, exame, raspagem e polimento dos dentes, inicialmente sob a supervisão dos CDs. Vale destacar que tais competências se deram em atividades clínicas postergadas pelos CDs em sua prática profissional cotidiana.

O desafio seguinte de Fones foi iniciar a programação com escolares. Empregou CDs para restaurar os primeiros molares permanentes dos alunos, enquanto higienistas cuidavam da prevenção. Ele constatou significativa redução das lesões de cáries ao final de cinco anos. Com esse feito, Fones inaugurou o primeiro serviço programático educacional, preventivo e assistencial dirigido a escolares.

Por tudo isso, três grandes méritos podem ser creditados a Fones: a divisão profissional do trabalho odontológico, mediante desoneração do CD, 
com consequente aumento da produtividade e da qualidade; o avanço da profissionalização da odontologia norte-americana enquanto empreendimento sociológico, político e econômico; e a 'invenção' da programação de serviços odontológicos.

Por outra parte, entre os defensores das enfermeiras dentais propostas por Rhein, coube a C. M. Wright (ADA, 1995-2008) treiná-las (no Ohio Dental College) para o trabalho escolar. Sob contestações dos CDs, seu programa funcionou de 1910 a 1914.

Entretanto, nos Estados Unidos, a proposta das higienistas foi a vitoriosa. Em 1915, Connecticut publicou uma segunda lei, regulando a prática de higienistas dentais e definindo o seu campo de atuação. Essa lei acabou servindo de modelo para que outros estados norte-americanos implantassem a legislação e criassem escolas profissionais.

Considerando a forma como se deu o avanço do processo de profissionalização no campo odontológico nos Estados Unidos, pode-se imputar a Fones e a seu opositor Wright um grande demérito: o distanciamento da saúde bucal norte-americana da enfermagem, dos centros de saúde e das famílias como espaços de práticas. Afinal, coube a eles consagrar a opção estratégica e preferencial da odontologia por territórios a serem ocupados independentemente da enfermagem; isto é, por fazer avançar o princípio profissional na divisão concorrencial do trabalho odontológico. Essa opção se disseminou internacionalmente e teve como consequência negativa a redução do escopo da participação da saúde bucal, em seu alcance comunitário, na grande empreitada civilizatória travada à época pelo higienismo.

\section{A contribuição neozelandesa}

A Nova Zelândia é um país composto por duas ilhas principais e numerosas pequenas ilhas, onde prevalecem cidades de até 3 mil habitantes e comunidades rurais (New Zealand, s.d.). Em 2007 todo o país contava com apenas 2.414 cirurgiões-dentistas praticantes (Thomson, 2006). Essas situações ajudam a compreender a emergência histórica de um tipo todo especial de auxiliar em odontologia: a enfermeira dental, hoje denominada terapeuta dental.

A Primeira Guerra Mundial (1914-1918) expôs a grave condição dos dentes dos recrutas neozelandeses. Estudos no imediato pós-guerra revelaram, entre outras coisas, que $90 \%$ das crianças requeriam cuidados bucais, muitas delas necessitando de próteses dentais (Hoskin, 2005). Como resultado, no início dos anos 1920 foi feito um apelo nacional pelo enfrentamento da questão da destruição dental, associando-o à cultura de mobilização para a guerra e suas táticas.

Inspirado no sucesso do modelo da enfermagem científica da Guerra da Crimeia, foi proposto o treinamento em saúde bucal de mulheres jovens, 
considerando que: a) a força de trabalho masculina sofrera fortes baixas com a guerra; b) havia muito trabalho higienista por fazer, desde sempre considerado 'trabalho decaído' pelos CDs; e c) não se tinha quantitativo de CDs para iniciativas de alcance nacional.

Sob o mote do princípio administrativo, a New Zealand Dental Association (NZDA) propôs enfermeiras dentais nas escolas como estratégia para o diagnóstico e os serviços restauradores (Leslie, 1971). Credita-se a sir Thomas A. Hunter, então diretor do Serviço Dental do Exército, sob desafios macroeconômicos e orientado por princípio administrativo (isto é, pela eficiência produtiva), o início dos serviços públicos escolares com enfermeiras dentais no país.

Analistas atribuem o sucesso do programa ao forte controle central; ao desenvolvimento de laços locais; à utilização de clínicas nas escolas; ao número fixo de pacientes para cada enfermeira; à limitação do tratamento às crianças registradas; às enfermeiras com escala ampliada de atribuições de diagnóstico, planejamento e execução do tratamento; e à baixa supervisão (Holt e Murray, 1980).

Uma avaliação de 1949 constatou um custo per capita baixo e média de 715 crianças por enfermeira. Em 1950, John Fulton, da Organização Mundial da Saúde (OMS), realizou estudo com 4.072 escolares, concluindo que o programa da Nova Zelândia obtivera sucesso em controlar os efeitos da cárie dental dos escolares mediante altos índices de tratamento, em que pesem os índices de prevalência de cárie continuar altos. Considerando as limitações das tecnologias preventivas da época, tal constatação em nada desabonava a importância dos serviços (Fulton, 1951).

No início dos anos 1980, Kennedy, citado por Corrêa (1982), afirmou que as enfermeiras haviam conseguido uma cobertura escolar quase universal entre os escolares neozelandeses: $96 \%$ deles recebiam tratamento odontológico adequado ofertado pelo programa e o número de extrações se reduzira a $0,18 \%$ dos alunos. E, entre os soldados, apenas $0,2 \%$ dos recrutas neozelandeses em 1976 necessitavam próteses.

Concluindo até aqui, vale destacar diferenças: a higienista dental norteamericana é produto do princípio profissional do tipo 'higienista', uma profissional autônoma treinada para a educação e a intervenção preventiva; já a enfermeira dental neozelandesa é produto do princípio administrativo do tipo 'operadora', uma profissional autônoma com foco principal na assistência clínica, ainda que com atuação na promoção e prevenção. Ambas compõem os modelos básicos de profissionais auxiliares com atuação direta na cavidade bucal. Além das diversas opções de mixagem desses dois tipos, abriram-se também novas possibilidades para o surgimento de profissionais auxiliares variados chamados 'técnicos'. 


\section{De tempos e movimentos, a emergência dos técnicos auxiliares}

De volta aos Estados Unidos, na década de 1940, temia-se a escassez de oferta profissional, uma vez que, desde aquela época e até hoje, sua população em geral cresce mais do que a população específica de dentistas. Diversos programas em universidades foram patrocinados para aumentar a eficiência da prática odontológica e dos serviços, objetivando alcançar maiores índices de produtividade mediante o estabelecimento de novos arranjos de auxiliares - orientados, portanto, por princípio administrativo.

No particular específico dos técnicos de nível médio e elementar, os estudos de Klein foram precursores (Soricelli, 1972). Em 1943, ele demonstrou que $33 \%$ mais pacientes eram atendidos quando o CD utilizava uma auxiliar para transferir materiais e instrumental. Esse aumento poderia chegar a $75 \%$, de acordo com o número de cadeiras com auxiliar. Surgiu assim a auxiliar instrumentadora (dental assistant).

Os estudos de Law, Johnson e Knutson (1953; 1955), iniciados em 1945 em Woonsocket, e de Waterman e Knutson (1953; 1954), iniciados em 1946 em Richmond, descreveram sobre auxiliares e sobre o sistema incremental em programas escolares. Demonstrou-se que um CD com uma auxiliar bem preparada ao lado da cadeira podia prestar atendimento a aproximadamente $50 \%$ mais pacientes e, com duas auxiliares (uma fixa e outra móvel), atingia cerca de $75 \%$ mais pacientes (Waterman, 1952). Portanto, esses estudos estabeleceram que, até então, a melhor forma de divisão de trabalho seria o uso de duas auxiliares, uma fixa, ao lado do CD (chair side assistant), e outra móvel (roving assistant), encarregada de assegurar o fluxo de pacientes, do trabalho de esterilização e demais operações de rotina.

Assim, desenvolveram-se métodos e técnicas mais simples e racionais capazes de aumentar a eficiência dos serviços, ampliando a cobertura a custos menores, bem como prevenindo stress e fadiga profissional.

Ao contrário das enfermeiras dentais neozelandesas, não foram delegadas funções para intervenção direta (dentística operatória) do auxiliar na cavidade bucal do paciente, nem se ousou conferir a eles a autonomia profissional, abolindo a supervisão direta do $\mathrm{CD}$. Nesses marcos, esse tipo de organização microeconômica do trabalho serviu de base para a concepção de um modelo racionalizador de tempos e movimentos, de organização do espaço, do processo de trabalho e de incorporação de novas tecnologias.

Até aqui, estavam bem marcados os limites que separavam os profissionais 'tipo norte-americanos' higienistas ou auxiliares instrumentadores dos profissionais 'tipo neozelandeses' operadores.

Entretanto, em 1947, Fulton propõe testar o sistema neozelandês nos Estados Unidos. Em 1949, Dunning (1958) começou a pôr em prática a 
proposta de dois anos de formação e cinco anos de produção experimental para higienistas dentais as quais, além de suas funções, atuavam como operadoras, inserindo material restaurador em cavidades abertas pelos CDs. Mesmo quando formando auxiliar para trabalho sob supervisão direta em experiência restrita ao âmbito interno de uma única instituição, mesmo quando tal experiência se dava mediante incentivos governamentais para estudos de aumento de produtividade e utilização de auxiliares com maiores delegações de funções, houve pronta reação profissional ao treinamento. E a American Dental Association (ADA) atuou fortemente para influenciar a proibição dessa e de outras experiências semelhantes. Porém, a despeito de tudo isso, Dunning manteve e realizou sua programação.

Sem se intimidar com a contenda com a ADA, em 1958, após a experiência realizada, Dunning publicou um trabalho propondo que os limites de produtividade clínico-operatória norte-americanos poderiam ser superados. Dunning defendeu o operador, nos termos do treinamento dado por ele, alegando o quanto o volume de restaurações nos Estados Unidos era menor que na Nova Zelândia e afirmando que ao menos a introdução de um técnico operador em cadeira própria junto do CD (sob supervisão direta), restaurando cavidades previamente abertas pelos CDs, aumentaria em $50 \%$ ou mais a já aumentada produtividade pelo modelo de Richmond e Woonsocket, que utilizava duas auxiliares (fixa e móvel). A American Dental Association House of Delegates reagiu e, em 1960, definiu expressamente o que não poderia ser incluído em treinamento de auxiliares: o máximo de delegações permitidas seriam as de auxiliar instrumentador e as de higienista dental (Soricelli, 1972).

Apesar disso, inspirada em Dunning, deu-se, uma década depois, uma nova experiência: a da Universidade do Alabama (Hammons e Jamison, 1968). Auxiliares foram treinados para colocação e remoção de diques de borracha; colocação e remoção de restaurações provisórias; colocação e remoção de porta-matrizes; condensação e escultura em restaurações de amálgamas em dentes previamente preparados; restauração com cimento de silicato e/ou resina acrílica em dentes previamente preparados; e acabamento e polimento das restaurações.

Todo esse conjunto amplo de práticas e estudos marcou a produção intelectual brasileira na área nas décadas de 1920, 1950, 1960 e 1970.

\section{Antecedentes nacionais da divisão do trabalho odontológico}

A ideia da divisão do trabalho odontológico no Brasil se deu sob três ideologias e três conjunturas distintas. As ideologias foram as do profissionalismo, da administração científica e da administração política. As conjunturas 
foram as da Reforma Sanitária dos anos 1920, do imediato pós-Segunda Guerra Mundial (anos 1950) e do declínio da ditadura militar brasileira, com o subsequente movimento da Reforma Sanitária, que se realizou politicamente no curso da Nova República.

\section{A divisão sob a ideologia do profissionalismo}

Chamamos aqui 'ideologia do profissionalismo' o discurso normal dos profissionais da odontologia brasileira e de suas lideranças tradicionais. É o discurso pautado nos elementos inerentes ao princípio profissional: autonomia, conhecimento, competência exclusiva, jurisdição exclusiva, credencialismo profissional, código de ética, autorregulação e governo privado da profissão, controle monopolista do mercado etc. (Freidson, 1988; Diniz, 2001).

No plano do senso comum, a doxa dos porta-vozes desse profissionalismo tradicionalista nunca expressou posições com clareza conceitual e tratamento teórico mínimos. Entre eles sempre faltaram alguns entendimentos sociológicos básicos, tais como o de que uma profissão é um produto de empreendimento social sobre uma ocupação. Nos marcos do 'empreendimento social', uma profissão, para manter-se eficaz, necessita se autorregular. No front da profissionalização, o controle do tamanho da comunidade se dá pela seleção dos novos praticantes, que são incorporados somente depois de ultrapassarem as barreiras de entrada. No front da desprofissionalização, o tamanho é controlado pelo expurgo dos antigos profissionais incapazes de ultrapassar as barreiras de permanência.

Para manter-se eficaz, a profissão necessita definir a qualidade daquilo de que os profissionais se ocupam: no front da profissionalização, selecionando as atividades profissionais que estão sendo adquiridas e valoradas em função da incorporação de novos conhecimentos esotéricos e tecnologias; e no front da desprofissionalização, repassando para profissões auxiliares conhecimentos e competências que foram postergados ou que sofreram desvaliação.

O controle do tamanho da comunidade e do alcance do campo de conhecimentos e competências exclusivas permite uma profissão se instituir, ganhar autonomia, fazer a gestão de suas fronteiras jurisdicionais e se manter eficaz. O descontrole das fronteiras causa a inflação de competências profissionais, seja pela aquisição de novas competências não esotéricas, seja pela manutenção de competências antigas que perderam tal caráter. É quando inflação e ineficácia corporativa corroem o status profissional.

Esse é o caso da odontologia brasileira, que, por não controlar o tamanho de sua comunidade de praticantes, não consegue assegurar o avanço da sua jurisdição sobre a prática de competência exclusiva e acaba inflacionada de atividades novas e não esotéricas. São criadas zonas de superposição e 
indefinição com outras profissões, minando o caráter diferenciado de sua prática, com prejuízos à assinação e ao reconhecimento social de privilégios (monopólios econômico, político e administrativo). Acaba inflacionada também pela incapacidade de depurar as tarefas clínicas degradadas, que deveriam ser repassadas, mas não o são, para profissões auxiliares.

A falta de compreensão sobre esses processos básicos entre os militantes do profissionalismo na odontologia brasileira resulta na ausência de uma agenda político-corporativa clara e em uma série de apostas cegas e outras ineficazes dos líderes desse profissionalismo tradicional. Dentre elas, destaca-se a negação puramente ideológica da ideia de incorporação de tecnólogos (de nível superior) ou mesmo de auxiliares técnicos (de nível médio) na divisão do trabalho clínico, historicamente representados pelos técnicos de saúde bucal (TSBs), nova nomenclatura definida em lei (Brasil, 2008). Decorrem também outras negações, tal como a da incorporação de profissionais de nível elementar na divisão do trabalho extraclínico, hoje representados pelo agente comunitário de saúde (ACS).

Nesses marcos ideológicos, sob princípio profissional, a divisão do trabalho odontológico aceita pelas lideranças tradicionais é tão somente aquela contida na ideia do simples auxiliar de consultório tradicional (de nível fundamental), hoje legalmente denominado de auxiliar de saúde bucal (ASB).

\section{A divisão sob a ideologia da administração científica}

\section{A administração científica na era Chagas}

Distinta da anterior, chamamos aqui 'ideologia da administração' o discurso de lideranças profissionais da odontologia brasileira que militam na saúde pública, um discurso pautado nos elementos inerentes ao princípio administrativo em três conjunturas distintas: a Reforma Carlos Chagas, dos anos 1920; o imediato pós-Segunda Guerra Mundial (anos 1950); e o declínio da ditadura militar brasileira, com o subsequente movimento da Reforma Sanitária.

Nos anos 1920, sob a liderança de Carlos Chagas, o Estado brasileiro começou o processo de instalação de uma estrutura assistencial própria de serviços básicos rotinizados de saúde: unidades locais inspiradas no modelo americano dos centros comunitários de saúde, com atividades coordenadas por sanitarista e trabalho realizado por enfermeira visitadora.

Nesse contexto, a emergência da enfermagem brasileira representava a tentativa de a ideologia administrativa ampliar suas ações, mediante a introdução do pulso social alóctone: o profissionalismo para a expansão das estruturas estatais. Isso porque a formação inicial das enfermeiras brasileiras, 
as enfermeiras visitadoras, era feita por médicos, de forma improvisada e incompleta. Em 1921, ela foi interrompida, depois que Chagas criou o Serviço de Enfermeiras, sob a direção de Ethel Parsons (Escola de Enfermeiras do Departamento Nacional de Saúde Pública, s.d.) e a incumbiu, no ano seguinte, de organizar um curso de formação de enfermeiras diplomadas. O segundo ano desse curso oferecia conteúdos de 'higiene da boca'. Foi o advento das enfermeiras diplomadas que levou à extinção do quadro das enfermeiras visitadoras leigas em 1926.

Em que pese toda ousadia político-institucional da Reforma Carlos Chagas sob o paradigma do higienismo, não foi possível consolidar práticas de saúde bucal na rotina visitadora. A proposição embutida na Reforma Carlos Chagas do trabalho higienista em saúde bucal não exclusivo da odontologia foi inadequada para o Brasil dos anos 1920. Primeiro, porque a proposta das enfermeiras, moderna ideia comunitarista norte-americana do trabalho básico em saúde, não encontrou acolhimento cultural no Brasil da época ao se confrontar com as orientações profissionais clínico-hegemônicas de inspiração francesa (médico e hospitalocêntricas). Segundo, porque as novas profissões semeadas pelo Estado obviamente não encontraram campo fértil para se desenvolverem exclusivamente no interior do Estado, uma vez que, para alcançar um pulso social vigoroso, característico do profissionalismo, elas dependeriam de ser aceitas em seu lugar próprio: o mercado. Porém não havia desenvolvimento global e independente desse mercado profissional no Brasil da época, faltando ambiência para o desenvolvimento do campo das profissões da saúde nessas bases. Terceiro, porque se dava no campo profissional da enfermagem e não no da odontologia.

Assim, a curiosa e contraditória tática brasileira de utilizar o avanço do profissionalismo como estratégia de expansão da ideologia administrada falhou: as visitadoras leigas foram extintas e as enfermeiras diplomadas foram paulatinamente cooptadas pelos serviços hospitalares da Era Vargas (Castro Santos e Faria, 2004), perdidas para as tradições europeias não comunitaristas e/ou médicas mais antigas. Por tudo isso, e outras coisas mais, dos anos 1930 até fins da Segunda Guerra Mundial houve uma desmobilização dos esforços em saúde pública.

Vale registrar que, para além da formação de enfermeiras, desde 1925, foram formadas educadoras sanitárias no Centro de Saúde Modelo do Instituto de Higiene de São Paulo para trabalho educacional domiciliar, no qual, segundo Faria (2006), também estava incluída a higiene bucal, ainda que não rotinizada.

No particular da odontologia brasileira, até os anos 1950, nada de mais substantivo se fez. Sem o profissionalismo da enfermagem e sem pulso profissional próprio para instituir auxiliares capazes de enfrentar o 'serviço decaído' da higiene bucal, essas práticas acabaram fora dos esforços que 
caracterizaram o higienismo brasileiro das primeiras décadas do século XX. Assim, a saúde bucal não cumpriu oportunamente sua missão civilizatória.

\section{A administração científica sespiana}

O segundo período histórico ocorreu na conjuntura da ideologia administrativa científica. Suas lideranças emergiram como atores políticos sobre os escombros da Segunda Guerra dispostas a expandir o aparelho de Estado e habilitá-lo para intervenções sociais sobre situações que o mercado não conseguia equacionar.

Nessa conjuntura, no setor saúde brasileiro, o princípio administrativo se colocou quase a nu. A motivação tipicamente weberiana, racional-legal, pautada na ética da responsabilidade, apresentou-se sob a roupagem do discurso sanitário ambientado nos elementos simbólicos e valores encarnados pelo 'sanitarismo sespiano'.

O Serviço Especial de Saúde Pública (Sesp) foi uma aposta no trabalho profissional administrado que reuniu tudo de mais avançado à época. Ele representa uma reedição revisada e ampliada do que fora proposto anteriormente, sob a mesma inspiração, pela Reforma Carlos Chagas e pelos esforços da Fundação Rockfeller no Brasil, desde os anos 1910 (Castro Santos e Faria, 2004). Constitui uma nova investida da visão comunitarista norteamericana contra a nossa cultura ancestral geral, tipicamente europeia continental e colonial não comunitarista, bem como contra nossa cultura ancestral particular da saúde, hospitalocêntrica à francesa (Santos, 1995).

Passada a guerra, nos anos 1950, o Sesp alcançou a questão da saúde bucal, promovendo uma profunda mudança no entendimento do modelo de atenção odontológica, ao fundar as políticas públicas subsetoriais sanitáriobucais. Servindo-se da ciência norte-americana, suas ações e serviços estruturaram duas modalidades de prática: a implantação de unidades escolares de atendimento odontológico na forma de 'sistema incremental', em 1951; e a implantação da fluoretação das águas de abastecimento público nas companhias municipais de água e esgotos, em 1953. A rede de serviços do Sesp foi instituída sob a lógica da programação (Zanetti, 1993). Pela primeira vez no Brasil, a divisão do trabalho odontológico é cientificamente racionalizada por princípio administrativo na figura da auxiliar de higiene dental (AHD), ultrapassando a ideia tradicional de simples auxiliar de consultório. Legatária da auxiliar norte-americana, com um número menor de delegações, concebida como uma espécie híbrida de instrumentadora e higienista, sem alcançar as atividades operadoras das enfermeiras dentais; a AHD foi inspirada nas experiências ainda não publicadas, à época, de Richmond e Woonsocket, adaptadas às condições nacionais por Frankel e Chaves. Formadas 
em serviços, introduziram no país o modelo de 'odontologia a quatro mãos' (Chaves, 1962).

O Sesp ainda tentou formar sua própria higienista dental, mas a experiência durou pouco. A formação universitária e outros fatores, em especial as resistências ideológicas dos CDs, fizeram que a formação da higienista fosse interrompida, novamente substituída pela de AHD. Contudo, as inovações na divisão do trabalho odontológico não se difundiram, ficaram limitadas ao âmbito do Sesp.

\section{A divisão sob a ideologia da administração política}

Chamamos aqui 'ideologia administrativa política' o discurso crítico de algumas lideranças profissionais da odontologia brasileira que militam na saúde coletiva. Esse discurso é pautado nos elementos inerentes aos princípios administrativos da Reforma Sanitária brasileira: eficácia social, eficiência econômica, bem-estar, justiça social (equidade) e aposta no trabalho profissional administrado nos marcos da institucionalidade do SUS. Herdeiros da tradição dos administradores científicos, ainda no contexto de fins da Guerra Fria, os administradores políticos emergiram como atores nos anos 1980 - como uma segunda geração de dentistas sanitaristas brasileiros -, sobre os escombros da administração pública militar, munidos de todo tipo de crítica à organização capitalista das práticas odontológicas no Brasil (Zanetti, 2003).

Essas críticas tinham, no mínimo, dupla inspiração. Primeiro, a crítica marxista ao mercado e ao Estado capitalistas, típica dos processos de transição democrática da América do Sul e do sul da Europa, que reverberou com grande intensidade no setor saúde brasileiro. Segundo, a crítica burocrática de corte welfariano à privatização do Estado, dados os efeitos do decreto-lei n. 200/1968 e sucedâneos, instrumentos da reforma administrativa militar, que instruíam os serviços públicos a participarem de forma complementar à iniciativa privada (Oliveira e Teixeira, 1985). Por isso, na odontologia pública brasileira de fins dos anos 1980, o processo institucional que ainda se destacava era o crescimento das modalidades de compra de serviços no mercado (convênios e credenciamentos) pelas estruturas de assistência à saúde da previdência social, posto que a saúde pública estatal era marginal (Viana, 1988).

Ao contrário da anterior, nessa segunda conjuntura, o princípio administrativo não se colocou a nu. A motivação tipicamente weberiana apresentouse sob a roupagem do discurso reformador sanitário para a Nova República, ambientado nos elementos simbólicos e valores da 'medicina comunitária' (Mendes, 1985), internacionalmente apresentados pela Assembleia Mundial de Saúde da OMS em Alma-Ata (antiga União Soviética), em 1978. 
O esgotamento da capacidade nacional de gerar inclusões pelo modelo de mercado, a inspiração internacional nos modelos welfarianos universais, a opção pela oferta de trabalho organizado por uma administração racionallegal do tipo burocrática e fordista, somados à repugnância marxista às instituições de mercado, entre outras coisas, num mix, resultaram na aposta pela oferta de serviços próprios, estatais, de base municipal, organizados num sistema nacional de saúde tardio, o SUS.

Sob tais inspirações, germinou a ideia de se difundir nacionalmente o modelo sespiano, ao se fazer a oferta pública de assistência odontológica mediante trabalho racionalizado (por critérios técnicos de uma administração científica) e organizado em linha (segundo os modelos fordista e taylorista).

No entanto, as origens de tudo isso, ironicamente, estão em mãos burocrático-autoritárias; mais especificamente no parecer n. 460, de 6 de fevereiro de 1975, do Ministério da Educação (MEC), aprovado pelo Conselho Federal de Educação, que instituiu as definições para a formação do técnico de higiene dental (THD) e do auxiliar de consultório dentário (ACD), como decorrência da reforma da educação de 1971, que instituiu o ensino profissional compulsório no segundo grau (Brasil, 1975). O parecer que inventa o THD amalgama inspirações norte-americanas e neozelandesas, fazendo do THD um herdeiro direto da experiência da AHD do Sesp e das pesquisas da Universidade de Alabama (Oliveira, 2008).

Mesmo desconhecendo o parecer do MEC, mesmo com outra nomenclatura (auxiliar com funções ampliadas), o THD ganha destaque nacional a partir de 1979, quando sai do papel no Distrito Federal com o Programa Integrado de Saúde Escolar da Fundação Educacional do Distrito Federal (PISE/FEDF/GDF), passando a ser alvo de intensa polêmica (Oliveira, 2008). Desde então, em seus trinta anos de existência jurídica infralegal, as funções auxiliares do THD foram cercadas dos mais diversos debates. Em geral, em seu apoio, estiveram e estão os sanitaristas reformistas (científicos ou políticos), pautados pelo princípio administrativo; e, em contestação a ele, colocam-se as lideranças profissionais da odontologia, pautadas pelo princípio profissional.

A figura do THD foi progressivamente incorporada como peça-chave nas propostas de racionalização dos administradores científicos e políticos. Entre os últimos, a ideia da divisão técnica rapidamente se torna bandeira político-administrativa porque, com ela, faz-se uma dupla crítica e uma afirmação: crítica à ineficiência produtiva e à injustiça social das práticas odontológicas de mercado; e afirmação do Estado como locus de práticas racionais. Simultaneamente, ocorreu na segunda metade dos anos 1970 uma onda internacional de pesquisas e desenvolvimento de tecnologias preventivas bucais tópicas com base em fluoretos. Ela teve considerável impacto no Brasil, inclusive com a formação da Associação Brasileira de Odontologia 
Preventiva (Aboprev), em 1981. Desde então, vem-se consolidando um paradigma de práticas com forte ênfase preventiva, que atingiu a formação clínica, e em saúde pública. Desde os inícios dos anos 1980 até hoje, tanto os administradores políticos que militaram no campo da medicina comunitária (que desembocará na saúde coletiva) quanto aqueles que militaram diretamente na esfera de influência da Aboprev comunicam-se entre si das mais variadas formas. Esse diálogo permitiu que a importância dada pelos administradores políticos ao trabalho do THD mudasse progressivamente de ênfase, passando da produção clínico-assistencial à atenção preventiva.

Em relação às propostas de mudanças no perfil profissional dessas ocupações técnicas auxiliares em odontologia, começam a aparecer algumas ideias novas, especialmente em relação ao THD. Um exemplo importante e polêmico refere-se à utilização do trabalho desse profissional principalmente na prevenção e no controle das doenças bucais, nos níveis individual e coletivo. Dessa forma, as atividades de inserção e condensação de substâncias restauradoras seriam preferencialmente executadas pelos próprios CDs. Isso evitaria a fragmentação do trabalho, aumentaria o grau de autonomia e resolutividade do THD e, possivelmente, resultaria num maior impacto epidemiológico na redução da cárie e da doença periodontal (Carvalho, 1998).

Percebe-se nessa citação de Carvalho, sub-repticiamente, que as práticas preventivas consolidaram seu significado como práticas profissionais auxiliares, isto é, como temas de domínio de uma cultura profissional não necessariamente intrínsecos à cultura em geral. Dessa forma, esse significado figura como um dos óbices à qualificação das práticas preventivas no bojo das pretensões promocionais mais amplas junto à cultura no geral.

Percebe-se, igualmente, que as concepções sobre o trabalho técnico auxiliar na odontologia provenientes da ideologia do profissionalismo tradicional e estribadas em fortíssimas resistências à ideia de que auxiliares participem de forma mais completa nas atividades de restauração dentária acabaram por convergir com as concepções oriundas da ideologia da administração política com ênfase na prevenção. Essa convergência foi materializada na programação dos serviços públicos odontológicos realizados na conjuntura hegemonizada pelos administradores políticos.

\section{As questões atuais da divisão do trabalho odontológico no Brasil: desgoverno profissional, saúde bucal na ESF e lei n. 11.889/2008}

\section{O desgoverno da odontologia brasileira}

A superoferta de força de trabalho odontológico no Brasil tem levado a odontologia a se afastar muito da dinâmica típica de evolução de uma profissão 
paradigmática. Cada vez mais as características degradantes se expressam, em particular, na forma de duas quedas: na seletividade dos novos conhecimentos e competências (redução do esoterismo) incorporados; e no volume de descarte dos antigos conhecimentos e competências que perderam seu esoterismo (perderam importância simbólica e profissional).

Vale destacar que, com a profissão líder incorporando conhecimentos com menos seletividade e repassando os saberes em menor quantidade, o processo de divisão do trabalho no campo profissional liderado pela odontologia foi inflacionado e truncado. Sob o imperativo da pletora profissional, o excedente descomunal de força de trabalho e sua dinâmica atípica vêm condenando inúmeros CDs à prática de conhecimentos e competências postergados e/ou decaídos, serviços não exclusivos que nunca foram considerados nobres pelos seus praticantes, e que há muito já deveriam ter sido repassados para profissões auxiliares.

Nessa odontologia se conforma, inflacionada, uma legião de CDs praticantes que milita numa zona de exercício profissional que, por sua nebulosa intransparência (quanto às suas perspectivas futuras) e na falta de nome melhor, podemos denominar de zona cinzenta da desprofissionalização. Nessa zona, não há cooperação, só competição, inclusive competição interprofissional direta entre dentistas e técnicos de saúde bucal.

\section{A ausência de processos sustentáveis de institucionalização, planejamento e programação da saúde bucal na ESF e de sua força de trabalho}

$\mathrm{O}$ advento do SUS, a municipalização da saúde e a ESF favoreceram a ampliação da força de trabalho odontológica nos serviços públicos. À primeira vista, a ESF aparenta ser favorável à administração e à melhor composição da força de trabalho nos serviços públicos. Isso porque a sua principal variável normativa, a distinção de equipes de saúde bucal (ESBs) (com ou sem TSBs), condiciona as transferências federais aos municípios - Piso de Atenção Básica (PAB) variável da saúde bucal.

Atualmente, com mais de 20 mil ESBs implantadas, observa-se que os postos de trabalho para CDs, TSBs e ASBs se distribuem formalmente da seguinte forma: $48 \%, 4 \%$ e $48 \%$, respectivamente (Brasil/MS/DAB, 2011). O gráfico dessa distribuição reproduz uma ampulheta perfeita, posto que a relação $\mathrm{CD} / \mathrm{ASB}$ é, ao menos em teoria, normativamente equilibrada. Na prática, a força de trabalho não corresponde exatamente aos postos de trabalho, uma vez que há inúmeras equipes com CD realizando jornadas de 20 horas semanais e auxiliares realizando jornadas de 40 horas semanais (um dos sintomas da precarização do trabalho no SUS).

De qualquer forma, vale destacar que a proporção de técnicos na ESF/SUS manteve-se praticamente inalterada quando comparada à sua par- 
ticipação na força de trabalho odontológica geral do país. Isso quer dizer que a expansão 'administrada' da oferta de trabalho odontológica no SUS não teve qualquer impacto sobre a expansão da força de trabalho dos técnicos. A presença do técnico no interior do sistema público continuou espelhando sua presença no mercado de livre concorrência. Nada novo surgiu, pois a principal norma de ampliação da saúde bucal na atenção básica do SUS não se sobrepôs às leis do mercado.

Tal inocuidade é explicada pela forma incremental (não racional) como essa política pública foi implantada: pressões político-eleitorais somadas a pressões político-profissionais para a expansão rápida, e a todo custo, do número de ESBs, laboratórios regionais de prótese e centros de especialidades odontológicas. Com isso, a implantação das ESBs não foi acompanhada de exigências administrativas racionais suficientes para expressá-la na lógica própria do planejamento, programação, acompanhamento, controle e avaliação. Também não se instituíram exigências de contrapartidas de estados e municípios, sejam elas contrapartidas financeiras (cofinanciamento federativo), políticas (ações de apoio à política nacional, tal como a realização de cursos, treinamento, capacitação, oficinas, entre outras medidas culturais específicas), ou técnicas (necessidade de demonstração de viabilidade e eficiência estrutural e operacional dos sistemas locais de saúde bucal etc.).

Nesse processo, o custeio passou a ser quase que exclusivamente federal, e as ausências de contrapartidas produziram inúmeras falhas de implantação. Os parcos recursos financeiros, os pouquíssimos recursos de organização e a quase nula institucionalização disseminaram uma implantação sem os devidos cuidados técnico-programáticos, criando dificuldades para a política nacional de saúde bucal se expressar de forma republicana (não patrimonialista) e federativa na maioria dos municípios brasileiros. No seu seio se instalaram fenômenos de subfinanciamento, ineficaciação, ineficientização, precarização, depreciação do potencial de oferta assistencial e de sua efetivação (Zanetti, 2005).

Esse fracasso também pode ser explicado, inter alia, pelo fato de as experiências exitosas de trabalho assistencial com divisão técnica do trabalho jamais terem sido tratadas como pilotos, como exemplares ou como referências para a institucionalização (normas); logo, não se multiplicaram. Na história recente, vê-se que no embate político sobre a divisão do trabalho odontológico, as profissões auxiliares, em especial o TSB, ficaram desprotegidas dos ataques da militância do profissionalismo.

Ainda hoje, o princípio profissional tradicional (social) tem sido mais forte que o princípio administrativo político na condução desses assuntos. Como se não bastasse, tudo ficou ainda mais difícil quando, nas duas últimas décadas, o princípio administrativo (técnico) passou a enfatizar a prevenção, despreocupando-se da assistência básica e, assim, convergindo para as teses do princípio profissional tradicional. 
Foi assim que o advento da saúde bucal na ESF (Brasil, 2000) reafirmou o viés preventista dos administradores políticos. Pouco se fez para estimular e acompanhar o trabalho dos auxiliares técnicos em atividades intrabucais diretas, de restauração dentária e periodontia básica. Consequentemente, a previsão da equipe modalidade II (com TDH) não se traduziu nem no volume, nem na qualidade da implantação assistencial necessária (Zanetti, Guimarães e Lima, 2006) à expansão qualificada da oferta.

Pode-se resumir toda crítica atual, no que diz respeito à composição da força de trabalho odontológica na ESF, na sua maior falha política, ou seja, orientar o trabalho do TSB para o preventivismo, e na maior falha normativa da política, de ter admitido o TSB como variável nas ESBs. Assim, hoje é possível implantar até oito tipos fundamentais de ESB (arranjos/paretos de recursos mobilizados). Desses, só quatro são formalmente eficazes (potentes) para assegurar garantia de acesso universal ao tratamento odontológico, isto é, para assegurar o tratamento clínico odontológico eletivo adequado ofertado pelo programa. Desses quatro, três são modalidade II (que exige TSB na ESB) e apenas um é modalidade I (não exige TSB na ESB). Porém, esse tipo de ESB, para se fazer eficaz, imputa um custo administrativo alto para os sistemas locais que o implementam: obriga a ESB a adscrever apenas 3 mil habitantes, ao passo que, na presença do técnico, a mesma ESB poderia adscrever o dobro (Zanetti, 2005).

Assim, na modalidade I, predominante no país, a garantia da universalização (se fosse essa a meta real) só se daria por redução da cobertura, dada a ausência do TSB na ESB. Nesses termos, dobra-se o custo unitário de cada alta clínica (tratamento completado - TC) - de $\mathrm{R} \$ 48,27$ para $\mathrm{R} \$ 77,24$ - e o custo unitário de implantação de cada ESB em um dado sistema local de saúde bucal. Em resumo, mesmo a melhor escolha em modalidade I (quando se opta pelo único arranjo eficaz para a universalização do acesso à assistência eletiva) é ineficiente (tem menor rendimento), ineficiência decorrente da baixa adscrição pela compensação da falta do TSB na ESB (Zanetti, 2010).

Um sistema nacional de atenção à saúde bucal é constituído por profissionais e unidades, como, parafraseando Poincaré (1905), uma casa é construída de tijolos, mas um amontoado de CDs, TSBs, ASBs, ACSs, ESBs, Unidades Básicas de Saúde da Família (UBSFs), Centros de Especialidades Odontológicas (CEOs), Unidades de Pronto-Atendimento (UPAs) e hospitais, da mesma forma que um monte de tijolos não é uma casa, não constituem um sistema público de atenção à saúde bucal.

É com preocupação pragmática (de melhorismo) que diagnosticamos, nos últimos dez anos, ter o importante acúmulo de recursos de Saúde Bucal no SUS, fruto do vigor ímpar da Política Nacional Brasil Sorridente, ampliado o número de ESBs na atenção básica, de laboratórios regionais de prótese 
dental e de CEOs na atenção especializada, mas ainda não tem sido capaz de ampliar a oferta de serviços mediante disposição calculada/justificada de seus recursos. Nesse contexto, os flagrantes prejuízos à utilidade e à justiça social da ação do Estado se tornaram evidentes e demonstráveis (Zanetti, 2005).

Num sistema local de atenção estruturado e consequente, de partida (isto é, do ponto de vista lógico-formal) a presença do TSB na assistência clínica é recurso fundamental; portanto, o TSB deveria ser tratado como uma constante. A sua ausência só deveria ser admitida como condição circunstancial e aprazada, no caso de ser necessário um tempo dedicado à formação de pessoal para os serviços (Zanetti, Guimarães e Lima, 2006).

Considerações técnicas sobre os problemas da política ajudam a sustentar a ideia não apenas de que a ausência de administração da força de trabalho odontológica no SUS é uma conjunção de legados e conjunturas históricas, mas também de que será muito difícil alcançar as garantias de universalização, justiça (equidade) e qualidade de oferta (integralidade, inclusive ao alcançar a oferta eletiva) sem mudanças culturais paradigmáticas que alcancem as lógicas do planejamento e da programação dessa força de trabalho e suas atividades.

\section{Avanços e limites da lei n. 11.889/2008}

À sombra das limitações culturais atuais, alguns líderes das corporações odontológicas têm saudado a lei n. 11.889/2008, que regulamenta o exercício das profissões de técnico em saúde bucal e de auxiliar em saúde bucal (Brasil, 2008), como um grande avanço. Essa disposição precisa ser mais bem analisada.

Em comparação com suas atribuições anteriores, o TSB, pela nova lei, adquiriu competências que, majoritariamente, são tão somente revisões e atualizações de competências anteriores do THD, não representando novas aquisições (exceção da competência para realizar isolamento de campo operatório). E perdeu as seguintes: realizar teste de vitalidade; educar e orientar pacientes ou grupos de pacientes sobre tratamento de doenças bucais; e responder pela administração da clínica. Essas perdas são consideráveis. No conjunto de perdas, não está claro se o TSB perdeu ou não as competências históricas de 'fechar' restaurações e de remover indutos e tártaro supragengival. Discutiremos isso com mais cuidado um pouco adiante.

Porém, não é propriamente a contabilidade de competências que melhor caracteriza os avanços e retrocessos da lei. A lei em si é o grande avanço, dado que o ordenamento jurídico ultrapassou a condição infralegal para ser expresso na forma de lei. Esse novo status jurídico dá às profissões odontológicas auxiliares recursos e garantias maiores, inclusive no que diz 
respeito ao Poder Judiciário, para eventuais disputas interprofissionais. Porém, em termos de contabilidade, a chave do cálculo dos avanços e limites não está na análise isolada das competências profissionais por profissão. Ela melhor se coloca quando os profissionais estão uns na presença dos outros. Então, possibilidades interpretativas inovadoras se configuram.

Para esse cálculo, é importante considerar que o legislador, para ordenar as relações interprofissionais do campo, compôs a lei utilizando a máxima comum de 'quem pode mais... pode menos', isto é, o cirurgião-dentista pode fazer tudo que é de sua competência exclusiva, como também pode fazer (não está impedido de) tudo o que é de competência do TSB, do ASB, do técnico em prótese dentária (TPD), do auxiliar em prótese dentária (APD) e do ACS. Assim, as competências profissionais dos auxiliares não anulam as competências profissionais dos CDs, tanto quanto as competências do ASB não anulam as competências profissionais dos TSBs; nada impede que o CD desempenhe competências profissionais de auxiliares (TSBs e ASBs). O mesmo vale para o TSB em relação às competências do ASB.

$\mathrm{Na}$ relação do CD com os auxiliares (TSB e ASB), a lei define que cabe ao CD: supervisionar e orientar os trabalhos dos TSBs (é indispensável a supervisão direta para trabalho clínico e a supervisão indireta para trabalho extraclínico) e dos ASBs; indicar técnica de remoção do biofilme para o TSB; indicar materiais e instrumentais odontológicos para restauração dentária direta; delegar supervisão do ASB ao TSB; e responder perante os Conselhos Regionais de Medicina pela extrapolação das funções específicas dos auxiliares. Não há na lei qualquer atribuição ao CD que o permita reduzir/cercear as competências profissionais dos auxiliares. Portanto, o CD não tem poderes para reduzir um TSB à condição de ASB; para limitar o TSB em seus direitos profissionais, agora afirmados e assegurados em lei. Também nada obriga o CD a realizar competências de TSBs quando na presença desses mesmos profissionais. Assim como nada obriga o TSB, quando na presença do ASB, realizar competências de ASB. Ideias de fazer tal trabalho em tais condições são contrassensos ao princípio do trabalho em equipe. Além disso, obrigar um CD a realizar regularmente competências profissionais de auxiliares (TSBs e ASBs), ou obrigar um TSB a realizar regularmente competências profissionais de ASB passa a configurar 'assédio moral' (Cordeiro, 2011).

\section{A principal questão da lei $n .11 .889 / 2008$}

Em que pesem os avanços reais, a nova lei deve ser compreendida com alguma reserva. O legislador não optou pela objetividade e pela positividade que toda lei pode ter sobre uma questão substantiva e conflitante. No caso particular, essas questões são as disputas interprofissionais 
CD versus TSB, que sempre dependeram de luta, de interpretação social, política e jurídica.

Assim, a lei é falha na definição sobre o direito profissional do TSB de realizar procedimentos operatórios restauradores e periodontais básicos intrabucais ('fechar restaurações' e remover tártaros e indutos).

O texto legal, em seu artigo 5, inciso VIII, reza ser competência do TSB, sempre sob supervisão do $\mathrm{CD}$, “inserir e distribuir no preparo cavitário materiais odontológicos na restauração dentária direta, vedado o uso de materiais e instrumentos não indicados pelo cirurgião-dentista". A falha do legislador se deu na redação do texto legal com frases em negativa e no uso do verbo 'distribuir'. Nesse particular crucial, caso a redação tivesse sido na forma afirmativa, ela afirmaria com clareza: compete ao TSB realizar intervenções operatórias dentais diretas nos pacientes, para fins de dentística restauradora, por meio da inserção do material restaurador até a completa finalização das restaurações, utilizando procedimentos, técnicas, materiais e instrumentais indicados pelo $\mathrm{CD}$, vetado tudo que não for indicado pelo CD para cada caso. No entanto, não é isso que está escrito; daí a confusão. Quanto à invenção do verbo distribuir (não usual nos compêndios das técnicas operatórias de dentística restauradora), ele manteve toda carga de subjetividade que historicamente paira sobre o conflito.

De acordo com as correntes antagônicas que se conformaram há décadas, hoje é possível interpretar a subjetividade da lei sobre os assuntos operatórios de dentística, no mínimo, de duas formas básicas: uma restritiva e outra ampla, porque hermenêutica.

A interpretação restritiva entende 'distribuir' como algo novo e distinto dos verbos e entendimentos usuais em dentística, a saber: inserir, condensar, esculpir, brunir e polir. Nesses termos, o uso de materiais restauradores pelo TSB fica muito limitado; na melhor das hipóteses, esse profissional só poderá 'fechar uma restauração' com ionômero de vidro, dado que a técnica da compressão digital coaduna com a ideia de um novo verbo operatório ('distribuir') e não implica ações associadas aos verbos operatórios tradicionais. Mas essa interpretação restritiva é herança de um profissionalismo arcaico de mercado. Ela é danosa à história, ao presente e ao futuro das relações interprofissionais e às necessidades produtivas do SUS, limitando o avanço do campo das profissões odontológicas.

Ao contrário, a interpretação hermenêutica não isola o verbo distribuir. Por ela, 'distribuir' é entendido em associação ao que se afirma ao final do mesmo parágrafo: “o uso de materiais e instrumentos indicados pelo cirurgião-dentista". Logo, se a indicação do CD é, por exemplo, de resina composta e o instrumental é o kit completo correspondente, fica claro que o conjunto de material e instrumental indicado cobra do TSB a competência para realizar toda e qualquer ação de isolamento, inserção, escultura e 
polimento com resina composta. Esse mesmo raciocínio vale para todos os demais materiais restauradores indicáveis.

Quanto ao segundo impasse, sobre se o TSB perdeu ou não a competência histórica da remoção de indutos e de tártaro supragengival, a discussão se dá em virtude do uso da palavra biofilme no texto legal. Essa palavra trouxe a questão da disputa interpretativa para o assunto da remoção de cálculos e indutos, isto é, para a operatória em peridontia básica, cujo entendimento e aceitação têm mais de cem anos (desde Rhein, no início do século XX). Na pragmática (uso) da palavra biofilme, ele não é tomada como sinônimo de cálculo: ninguém fala 'biofilme mineralizado' tanto quanto ninguém chama gelo de 'água solidificada'. Pelos mesmos motivos associados à ideia de 'não fechar restaurações', a interpretação estritamente clínica de biofilme seria igualmente danosa à oferta odontológica no SUS. Por isso, uma 'licença técnica' para uma interpretação mais ampla do conceito de biofilme acaba por ser uma postura mais adequada à boa administração dos serviços públicos odontológicos e às suas exigências constitucionais expressas.

Infelizmente, porém, o legislador não definiu com clareza e objetividade as competências do TSB nos procedimentos operatórios restauradores e periodontais básicos intrabucais. Assim, a antiga contenda histórica da dentística continua, e uma nova contenda na periodontia foi aberta. Fica mantida a disputa interpretativa, agora ao alcance do Judiciário e de sua jurisprudência.

Considerando que o Brasil é um país de transição epidemiológica bucal incompleta, o problema interpretativo sobre a participação dos TSBs nos procedimentos operatórios restauradores intrabucais coloca novas dificuldades para a tarefa pública de se saldar uma dívida assistencial secular. Já o problema sobre a participação dos TSBs nos procedimentos periodontais básicos intrabucais coloca uma dificuldade administrativa para a eficiência clínica adequada à demanda futura predominante: a demanda de parcelas crescentes da população brasileira que, incluídas, já completaram sua transição epidemiológica bucal e sua transição demográfica. Portanto, essa questão é um problema jurídico-institucional presente colocado para o futuro da divisão do trabalho clínico-odontológico no SUS.

Por fim, vale observar também que, no âmbito do SUS, a falta de orientação administrativa clara das coordenações municipais, estaduais e nacional de saúde bucal a favor da interpretação hermenêutica da lei tem contribuído muito para a multiplicação, país afora, da interpretação restrita e prejudicial à maior organização assistencial e ao aperfeiçoamento da oferta de qualidade no SUS. 


\section{Conclusão}

Interessa-nos destacar algumas conclusões mais propriamente políticas, colocando em evidência o fato de que nas últimas três décadas muito pouco daquilo que foi proposto como divisão do trabalho pelos administradores políticos teve tradução ampla no país. Houve um congelamento histórico, quiçá involução, dessas questões ao longo das conjunturas políticas da Nova República. O balanço político dessa história contemporânea específica serviu para demonstrar que:

- as opiniões e disputas atuais não estão sendo suficientemente informadas, e o debate acabou limitado ao discurso ideológico, pois não tem existido suficiente incursão nos saberes da sociologia, economia, política, história e antropologia das profissões para explorar a odontologia brasileira como fenômeno profissional e objeto teórico em pesquisas científicas de saúde bucal coletiva;

- os dois fundamentos ideológicos na formulação crítica daqueles que hoje se encontram em postos de poder - anticapitalismo e racionalização - poderiam ser dissociados;

- o curso da aposta racional-legal poderia almejar a inclusão e a justiça sociais por outras vias de mudanças, sem implicar necessariamente a racionalização da divisão técnica do trabalho. Viu-se que a ampliação da oferta de serviços próprios de saúde bucal seria mais tangível com esforços políticos capazes de incluir a saúde bucal na agenda das políticas públicas de ampliação da atenção no SUS, mesmo utilizando serviços não racionalizados, ineficazes e ineficientes;

- a lógica de planejamento/programação e a antiga questão da divisão técnica do trabalho em saúde bucal e da eficiência da produção poderiam ser deslocadas para um momento futuro qualquer, ainda hoje postergado.

$\mathrm{Na}$ prática, durante o regime burocrático-autoritário, quando havia poucas possibilidades reais de se ampliar a oferta dos serviços públicos, a ideia da racionalização administrativa do trabalho odontológico com ênfase no trabalho do técnico avançou apenas como bandeira política. Depois, já no regime democrático, quando as possibilidades de mudanças efetivas foram descortinadas pelo acontecimento de políticas públicas universalistas no interior do SUS, outras bandeiras políticas foram vislumbradas, fazendo os projetos ancestrais da racionalização e da expansão dos auxiliares de nível técnico se tornarem óbices políticos à sustentação e à ampliação do arco de alianças que dá governabilidade ao subsetor. Com tudo isso, ainda não se cumpriu a antiga promessa militante da racionalização organizacional do trabalho odontológico no SUS em bases tecnicamente justificáveis. 


\section{Nota do Editor}

Este trabalho é produto de contribuições de parte de dissertação de mestrado (Oliveira, 2008) e parte de tese de doutorado (Zanetti, 2005), financiadas por meio de bolsa Fiocruz e bolsa CNPq, e de linha de pesquisa financiada pela Rede de Observatório de Recursos Humanos em Saúde (ObservaRH), do Núcleo de Estudos em Saúde Pública, do Centro de Estudos Avançados Multidisciplinares da Universidade de Brasília (NESP/CEAM/UnB).

\section{Colaboradores}

Carlo Henrique Goretti Zanetti e José Antônio Abreu de Oliveira trabalharam juntos em todas as etapas de produção do ensaio. Maria Helena Magalhães de Mendonça foi orientadora da dissertação de mestrado citada na Nota do Editor e contribuiu com pareceres no processo de elaboração do texto. Esse artigo contou com sugestões de redação importantes de Tiago Coelho de Souza (UnB), Nilce Santos de Melo (UnB) e Lana Bleicher (UFBA).

\section{Notas}

1 Professor do Curso de Odontologia da Faculdade de Saúde da Universidade de Brasília (UnB), Brasília, Distrito Federal, Brasil. Doutor em Saúde Pública pela Escola Nacional de Saúde Pública Sergio Arouca, Fundação Oswaldo Cruz (Ensp/Fiocruz). <zanetti@unb.br> Correspondência: Departamento de Odontologia, Faculdade de Ciências da Saúde, Universidade de Brasília, Campus Universitário Darcy Ribeiro, Asa Norte, Brasília, DF, Brasil, CEP 70910-900.

2 Cirurgião-dentista da Prefeitura Municipal de Varre-Sai, Rio de Janeiro, Brasil. Mestre em Saúde Pública pela Escola Nacional de Saúde Pública Sergio Arouca, Fundação Oswaldo Cruz (Ensp/Fiocruz). <cdjose@bol.com.br>

3 Pesquisadora do Núcleo de Estudos Político-Sociais em Saúde e professora de pósgraduação stricto sensu no Departamento de Administração e Planejamento em Saúde da Escola Nacional de Saúde Pública Sérgio Arouca, Fundação Oswaldo Cruz (Ensp/Fiocruz). $<$ mhelenam@ensp.fiocruz.br> 


\section{Referências}

AMERICAN DENTAL ASSOCIATION (ADA). History of dentistry. 1995-2008. Disponível em: <www.ada.org/public/resources/history/ timeline_20cent.asp > . Acesso em: 20 abr. 2006.

BASTOS, Nilo Chaves de Brito. Sesp/Fsesp: 1942 - evolução histórica. 2. ed. Brasília: Fundação Nacional de Saúde, 1996.

BRASIL. Lei n. 11.889, de 24 de dezembro de 2008: regulamenta o exercício das profissões de Técnico em Saúde Bucal - TSB e de Auxiliar em Saúde Bucal - ASB. Diário Oficial da União, Brasília, n. 251, seção 1, p. 2, 26 dez. 2008.

Ministério da Educação e Cultura. Conselho Federal de Educação. Parecer n. 460, de 6 de fevereiro de 1975: dispõe sobre a habilitação em nível de $2^{\circ}$ grau de Técnico em Higiene Dental e Atendente de Consultório Dentário. Diário Oficial da República Federativa do Brasil, Brasília, Documenta, v. 171, p. 20-26, 6 fev. 1975.

Ministério da Saúde. Portaria GM/MS n. 1.444 , de 28 de dezembro de 2000: estabelece incentivo financeiro para a reorganização da atenção à saúde bucal prestada nos municípios por meio do Programa de Saúde da Família. Diário Oficial da União, Brasília, v. 138, n. 250, seção 1, p. 85, 29 dez. 2000.

Departamento de Atenção

Básica. Evolução do credenciamento e implantação da Estratégia Saúde da Família. Brasília: Ministério da Saúde. Disponível em $<$ http://dab.saude.gov.br/cnsb/historico_ cobertura_sf.php >. Acesso em: 4 out. 2001.

CARVALHO, Cristiane Leite. Guia curricular para formação do atendente de consultório dentário para atuar na rede básica do SUS. Brasília: Ministério da Saúde, 1998. V. 2, Área Curricular IV, Texto n. 5.

CASTRO SANTOS, Luiz Antonio de; FARIA, Lina Rodrigues de. Cooperação internacional e a enfermagem de saúde pública no
Rio de Janeiro e São Paulo. Revista Horizontes, Bragança Paulista, v. 22, n. 2, p. $123-$ 150, jul.-dez. 2004.

CHAVES, Mário M. Odontologia social. Washington: PAHO, 1962

COELHO, Edmundo Campos. Físicos, sectários e charlatães: a medicina em perspectiva histórico comparada. In: MACHADO, Maria Helena (Org.). Profissões de saúde: uma abordagem sociológica. Rio de Janeiro: Editora Fiocruz, 1995.

CONSELHO FEDERAL DE ODONTOLOGIA. Resolução CFO n. 63, de 8 de abril de 2005: aprova a Consolidação das Normas para Procedimentos nos Conselhos de Odontologia. Diário Oficial da União, Brasília, seção 1 , p. 104, 19 abr. 2005.

CORDEIRO, Tereza Martins Garcia. Profissão TSB [mensagem pessoal]. Mensagem recebida por zanetti@unb.br em: 14 jan. 2011.

CORRÊA, Maria das Dores Pinheiro. Utilização de pessoal auxiliar em odontologia: Delegações de funções. 1982. Dissertação (Mestrado em Saúde Pública) - Faculdade de Saúde Pública, Universidade do Estado de São Paulo, São Paulo, 1982

DINIZ, Marli. Os donos do saber: profissões e monopólios profissionais. Rio de Janeiro: Revan, 2001.

DUNNING, James M. Extending the Field for Dental Auxiliary Personnel in the United States. American Journal of Public Health, Washington, v. 48, n. 8, p. 1.059-1.064, 1958.

ESCOLA de Enfermeiras do Departamento Nacional de Saúde Pública. In: CASA DE OSWALDO CRUZ (COC). Dicionário histórico-biográfico das ciências da saúde no Brasil (1832-1930). Rio de Janeiro: Casa de Oswaldo Cruz, [s.d.]. Disponível em: $<$ www.dichistoriasaude.coc.fiocruz.br/iah/ $\mathrm{P} /$ verbetes/escenfan.htm $>$. Acesso em: 12 jul. 2011. 
FARIA, Lina Rodrigues de. Educadoras sanitárias e enfermeiras de saúde pública: identidades profissionais em construção. Cadernos Pagu, Campinas, n. 27, p. 173-212, 2006. Disponível em: <www.scielo.br/scielo. php?script $=$ sci_arttext $\&$ pid $=$ S0 $104-$ $83332006000200008 \& \operatorname{lng}=\mathrm{en} \& \mathrm{nrm}=\mathrm{iso}>$. Acesso em: 10 mar. 2009.

FREIDSON, Eliot. Renascimento do profissionalismo: teoria, profecia e política. São Paulo: Edusp, 1988.

FULTON, John T. Experiment in Dental Care: Results of New Zealand's Use of School Dental Nurses. Bulletin of the World Health Organization, Geneva, v. 4, n. 1, p. 1-73, 1951.

HAMMONS, Paul E.; JAMISON, Homer C. New Duties for Dental Auxiliaries: The Alabama Experience. American Journal of Public Health and the Nation's Health, New York, v. 58, n. 5, p. 882-886, 1968.

HOLT, Ruth D.; MURRAY, John J. An Evaluation of the Role and Clinical Contribution of New Cross Dental Therapists. Journal of the Royal Society of Medicine, Londres, v. 73, n. 3, p. 187-190, Mar. 1980.

HOSKIN, Sorrel. Open Wide: Dental Nursing History. New Plymouth: Puke Ariki, 2005. Disponível em: <www.pukeariki.com/ Research/TaranakiStories/TaranakiStory/ id/602/title/open-wide-dental-nursinghistory.aspx>. Acesso em: 15 mar. 2011.

KLEIN, Henry. Civilian Dentistry in Wartime. Journal of the American Dental Association, Chicago, v. 31, n. 9, p. 648-661, 1944.

LAW, Frank E.; JOHNSON, Carl E.; KNUTSON, John W. Studies on Dental Care Services for School Children-First and Second Treatment Series at Woonsocket, Rhode Island. Public Health Reports, Rockville, v. 68, n. 12, p. 1.192-1.198, 1953.

Studies on Den-

tal Care Services for School Children-Third and Fourth Treatment Series at Woonsocket, Rhode Island. Public Health Reports, Rockville, v. 70, n. 4, p. 402-409, 1955.

LESLIE, G. H. More about Dental Auxiliaries. Australian Dental Journal, Melbourne, v. 16, n. 4, p. 201-209, 1971.

MENDES, Eugênio Vilaça. A evolução histórica da prática médica, suas implicações no ensino, na pesquisa e na tecnologia médicas. Belo Horizonte: PUC-MG/Finep, 1985.

MILLER, Willoughby Dayton. Micro-Organisms of the Human Mouth: The Local and General Diseases which Are Caused by Them. Philadelphia: S. S. White Dental Manufacture Company, 1890.

MOTLEY, Wilma E. Founding the Dental Hygiene Profession. In: AMERICAN DENTAL HYGIENISTS' ASSOCIATION. American Dental Hygienists' Association 75th Anniversary Scrapbook. Chicago: American Dental Hygienists' Association, 1983. Disponível em: <www.adha.org/downloads/ history/partl.pdf $>$. Acesso em: 11 mar. 2009.

NEW ZEALAND. STATISTICS NEW ZEALAND. Population. Wellington: Statistics New Zealand, [s.d.]. Disponível em: <www. stats.govt.nz/products-and-services/newzealand-in-profile-2009/population.htm>. Acesso em: 10 mar. 2009.

OLIVEIRA, Jaime A. de Araújo; TEIXEIRA, Sônia M. Fleury. (Im)Previdência Social: 60 anos de história da Previdência no Brasil. Petrópolis: Vozes, 1985.

OLIVEIRA, José Antônio Abreu de. O técnico de higiene bucal: trajetória e tendências de profissionalização com vista ao maior acesso aos serviços de saúde bucal. 2008. Dissertação (Mestrado em Saúde Pública) Escola Nacional de Saúde Pública Sérgio Arouca, Fundação Oswaldo Cruz, Rio de Janeiro, 2008.

POINCARÉ, Henri. Science and Hypothesis. Londres: Walter Scott, 1905. Disponível 
em: <http://abu.cnam.fr/cgi-bin/donner_ html?scihyp2>. Acesso em: 20 jun. 2011.

PROGRESSIVISM in the United States. In: WIKIPEDIA. San Francisco: Wikimedia Foundation, [s.d.]. Disponível em: <http:// en.wikipedia.org/wiki/Progressivism_in_ the_United_States $>$. Acesso em: 15 mar. 2011.

SANTOS, Pedro Miguel dos. Profissão médica no Brasil. In: MACHADO, Maria Helena (Org.). Profissões de saúde: uma abordagem sociológica. Rio de Janeiro: Ed. Fiocruz, 1995. p. 97-117.

SÃO PAULO. PODER LEGISLATIVO. Lei estadual n. 12.250, de 9 de fevereiro de 2006: veda o assédio moral no âmbito da administração pública estadual direta, indireta e fundações públicas. Diário Oficial do Estado, São Paulo, p. 6, 10 fev. 2006.

SORICELLI, David A. Implementation of the Delivery of Dental Services by Auxiliaries: The Philadelphia Experience. American Journal of Public Health, Washington, v. 62, n. 8, p. 1.077-1.087, 1972.

THOMSON, W. M. 2006 Workforce Analysis. Wellington: Dental Council of New Zealand, 2007. Disponível em: <www.dentalcouncil.org. nz/Documents/Reports/WorkforceAnalysis 2006.pdf >. Acesso em: 10 mar. 2009.

TOCQUEVILLE, Alexis de. A democracia na América. 4. ed. Belo Horizonte: Itatiaia, 1987.

VASCONCELLOS, Maria do Carmo Costa. O assistente odontológico na equipe de prestação de serviços odontológicos. Revista de Saúde Pública, São Paulo, v. 14, n. 1, 1980. Disponível em: <www.scielo.br/ scielo.php?script $=$ sci_arttext $\&$ pid $=$ S003489101980000100010>. Acesso em: 15 mar. 2011.

VIANA, Maria Isabel Pereira. Estado e atenção odontológica no Brasil: um estudo sobre as políticas de saúde bucal na conjuntura pós-74. 1988. Dissertação (Mestrado em
Medicina) - Faculdade de Medicina, Universidade Federal da Bahia, Salvador, 1988.

WALLS, R. M. Use of Auxiliary Personnel in Dental Care Programs. American Journal of Public Health and the Nation's Health, New York, v. 39, n. 4, p. 517-524, April, 1949.

WATERMAN, George E. Effective Use of Dental Assistants. Public Health Reports, Rockville, v. 67, n. 4, p. 390-393, 1952.

WATERMAN, George E.; KNUTSON, John W. Studies on Dental Care Services for School Children: First and Second Treatment Series at Richmond, Indiana. Public Health Reports, Rockville, v. 68, n. 6, p. 583-589, 1953.

; . Studies on Dental Care Services for School Children: Third and Fourth Treatment Series at Richmond, Indiana. Public Health Reports, Rockville, v. 69, n. 3, p. 247-254, 1954.

ZANETTI, Carlo Henrique Goretti. A utilidade como função para universalidade $e$ equidade: uma análise formal da validade instrumental do ordenamento administrativo federal da assistência à saúde bucal no saúde da família. 2005. Tese (Doutorado em Saúde Pública) - Escola Nacional de Saúde Pública Sérgio Arouca, Fundação Oswaldo Cruz, Rio de Janeiro, 2005. Disponível em: <http://bvsms.saude.gov.br/bvs/publicacoes/ premio2006/carlo_zanetti_D_MH.pdf $>$. Acesso em: 26 abr. 2012.

As marcas do mal-estar social no sistema nacional de saúde tardio: o caso das políticas de saúde bucal, no Brasil dos anos 80. 1993. Dissertação (Mestrado em Saúde Pública) - Escola Nacional de Saúde Pública Sérgio Arouca, Fundação Oswaldo Cruz, Rio de Janeiro, 1993. Disponível em: <www. saudebucalcoletiva.unb.br/oficina/estado/ politicas/1reforma_estado.htm\#dissertacao $>$. Acesso em: 26 abr. 2012.

Opinião: A inclusão da saúde bucal nos PACS/PSF e as novas possibilidades de 
avanços no SUS. 2001. Disponível em: $<$ www.saudebucalcoletiva.unb.br/oficina/ estado/coletivo_amplo/1coletivo_amplo.htm\# opiniao_ms>. Acesso em: 26 abr. 2012.

Pesquisa Razões práticas: utilidade e justiça na alocação do Técnico de Higiene Dental (THD) para a oferta assistencial programada do PSF (aferindo a validade externa do instrumento de pesquisa). Brasília: UnB/CEAM/NESP/ObservaRH, 2010.

Saúde bucal no Programa de Saúde da Família (PSF): proposição e programação. 2000. Disponível em: <ftp://164.41.147.200/ oficina/estado/coletivo_amplo/proposta_ geral_SBF.doc >. Acesso em: 26 abr. 2012.

ZANETTI, Carlo Henrique Goretti; GUIMARÃES, Palmira; LIMA, Marina A. Umbelina de. Pesquisa Razões práticas: utilidade e justiça na alocação do Técnico de Higiene Dental (THD) para a oferta assistencial programada do PSF (aferindo a validade externa do instrumento de pesquisa). Brasília: UnB/CEAM/NESP/ObservaRH, 2006. Disponível em: <www.observarh.org.br/nesp/ sistema/banco/20070815085933_thd_oferta_ assist.pdf > . Acesso em: 26 abr. 2012.
ZANETTI, Carlo Henrique Goretti; OLIVEIRA, José Antônio Abreu de; LIMA, Marina A. Umbelina de. Para dividir o trabalho odontológico: a hermenêutica da administração e profissão na divisão do trabalho das atividades não exclusivas (não privativas) do $\mathrm{CD}$ entre TSB, ASB e ACS nas equipes de saúde da família com saúde bucal modalidade II. Brasília: UnB/CEAM/NESP/ObservaRH, 2009. (Projeto em andamento). Disponível em: $<$ www.saudebucalcoletiva.unb.br/pesquisa/ arearestrita/projeto.pdf $>$. Acesso em: 26 abr. 2012.

Recebido em 20/10/2011

Aprovado em 07/02/2012 